\title{
Effects of laparoscopic adjustable gastric banding on sleep and metabolism: a I2-month follow-up study
}

This article was published in the following Dove Press journal:

International Journal of General Medicine

20 November 2012

Number of times this article has been viewed

\author{
Ana C Krieger' \\ Heekoung Youn ${ }^{2}$ \\ Frank Modersitzki \\ Ya-Lin Chiu' \\ Linda M Gerber \\ Elizabeth Weinshel ${ }^{2}$ \\ Christine R Fielding ${ }^{2}$ \\ 'Weill Cornell Medical College and \\ New York Presbyterian Hospital, \\ ${ }^{2}$ New York University School \\ of Medicine and NYU Langone \\ Medical Center, New York, NY
}

Correspondence: Ana C Krieger Weill Cornell Medical College, Center for Sleep Medicine, 425 East 6I st Street, Fifth Floor, New York, NY, USA 10065

Tel +l 6469627378

Fax + I 6469620455

Email ack2003@med.cornell.edu
Background: Obstructive sleep apnea is commonly associated with metabolic changes and obesity, and changes in body weight by either medical or surgical approaches have been considered to affect the severity of sleep apnea and appetite-controlling hormones. This prospective study evaluated the effect of weight loss induced by laparoscopic adjustable gastric banding (LAGB) surgery on respiratory disturbance during sleep, oxygen saturation levels, sleep architecture, and leptin and ghrelin levels.

Methods: Participants were patients at a university-based medical center surgical weight loss program. All participants with a body mass index $>30 \mathrm{~kg} / \mathrm{m}^{2}$ undergoing LAGB surgery for weight reduction were offered the opportunity to participate in the study. Procedures included overnight polysomnography followed by fasting hormone levels at baseline and 12 months postoperatively.

Results: Thirty subjects (10 men, 20 women) of mean age $44.0 \pm 12.5$ years were recruited. At 12 months postoperatively, mean excess weight loss was $44.4 \% \pm 14 \%$. The apnea-hypopnea index decreased from $34.2 \pm 35$ to $19.0 \pm 21.7$ events per hour $(P<0.0001)$, while leptin levels decreased from $24.5 \pm 17.42 \mathrm{pg} / \mathrm{mL}$ to $11.6 \pm 10.6 \mathrm{pg} / \mathrm{mL}(P=0.02)$. Ghrelin levels did not change substantially. Nadir oxygen saturation levels increased from $81 \%$ to $84 \%$ at 12 months $(P=0.03)$. Mean oxygen saturation improved and was positively correlated with ghrelin levels at both time points $(\mathrm{r}=0.39, P=0.07$, and $\mathrm{r}=0.60, P=0.01)$.

Conclusion: LAGB surgery was associated with 44.4\% excess weight loss at 12 months, accompanied by a $33.7 \%$ improvement in apnea-hypopnea index as well as a reduction in leptin levels by $31.7 \%$ in this group. An association between ghrelin and mean oxygen saturation was seen and deserves further investigation.

Keywords: sleep apnea, obesity, bariatric surgery, weight loss, metabolism, leptin, ghrelin, sleep

\section{Introduction}

Obstructive sleep apnea (OSA) is a condition characterized by recurrent episodes of partial or complete airway obstruction associated with decreases in oxygen saturation levels and arousals from sleep. Obesity is its most common predisposing factor, with a 10 -fold increase in risk associated with body mass index $>30 \mathrm{~kg} / \mathrm{m}^{2}{ }^{1}$ Visceral obesity is more commonly associated with OSA than other forms of obesity. ${ }^{2-4}$ Changes in sleep have been shown to affect the levels of neuroendocrine factors that regulate hunger and appetite. Leptin is an adipocyte-derived hormone that suppresses appetite, and lower levels have been documented in obese subjects, with improvement after weight loss. ${ }^{5}$ Ghrelin, predominantly a stomach-derived peptide, stimulates appetite and its 
association with OSA and weight loss is still under debate. ${ }^{6}$ Metabolic changes often seen in patients with OSA resemble metabolic syndrome and prediabetes. ${ }^{7,8}$

Sustained weight reduction has been difficult to achieve using dietary and lifestyle modifications. Laparoscopic adjustable gastric banding (LAGB) surgery provides a reliable, safe, minimally invasive approach to weight loss. ${ }^{9}$ The LAGB procedure provides the benefits of a minimally invasive surgery, lower perioperative morbidity, faster postoperative recovery, and potential reversibility compared with more invasive procedures. This prospective study was designed to evaluate the effects of weight loss on respiratory disturbance during sleep, sleep architecture, and levels of leptin and ghrelin in a group of morbidly obese patients undergoing surgery using the Lap-Band $^{\circledR}$ (Allergan, Santa Barbara, CA) technique for weight reduction.

\section{Methods and materials}

All patients scheduled to undergo laparoscopic bariatric surgery at our university hospital for weight reduction using the Lap-Band technique were offered participation in this study. The study procedures involved clinical assessment, overnight sleep study, and measurements of leptin and ghrelin at baseline and 12 months postoperatively. Patients served as their own controls, with blood samples and measurements obtained before surgery and 12 months after laparoscopic bariatric surgery. Clinical assessment consisted of review of medical history, physical examination, vital signs, and height and weight measurements. An informed consent form approved by the institutional review board (10321) was signed by all the participants.

\section{Laparoscopic gastric banding procedure}

The LAGB procedure for weight reduction was performed by implantation of a Lap-Band (an adjustable silicone gastric band) circumferentially around the uppermost part of the stomach, 1-2 cm inferior to the gastroesophageal junction, to create a $15 \mathrm{~mL}$ gastric pouch. The band was locked and secured in place with anterior gastro-gastric suture plication with a running, nonabsorbable suture, and connected via tubing to a titanium access port that is secured extraperitoneally to the anterior rectus sheath so the reservoir may be subsequently accessed percutaneously. Normal saline solution was injected to tighten the band. ${ }^{10}$ Patients were monitored clinically under the care of the surgical team and returned for follow-up visits on a monthly basis for band adjustment as needed. Weight loss was reported as percentage of weight loss, percentage of excess weight lost, and percentage of excess body mass index lost.

\section{Overnight sleep study}

An attended nocturnal polysomnography was performed.

Recorded channels included electroencephalogram, electrooculogram, submental and anterior tibialis electromyogram, electrocardiogram, inductive plethysmography, body position, nasal cannula/pressure transducer, and oximetry. Polysomnographic data were scored by a single sleep research technician according to American Academy of Sleep Medicine rules. The apnea-hypopnea index (AHI) was calculated and reported based on sleep stage and body position, generating the rapid eye movement sleep AHI and supine AHI values. The mean and lowest oxygen saturation values were also recorded, as well as the percentage of sleep time spent at saturation levels below $90 \%$.

\section{Leptin and ghrelin measurements}

Morning blood samples were collected at the end of an 8-hour fasting period, prior to breakfast, following overnight polysomnography. Plasma samples were stored at $-20^{\circ} \mathrm{C}$ until examined for concentrations of leptin and total ghrelin by specific enzyme-linked immunoassays. Plasma leptin concentrations were determined by a sandwich immunoassay (R\&D Systems, Minneapolis, MN) which has a 3.2\% intra-assay variability and a $4.1 \%$ interassay variability, as reported by the manufacturer. Total ghrelin concentrations were determined using a competitive immunoassay (Phoenix Pharmaceuticals Inc, Burlingame, CA) with intra-assay and interassay variabilities of $5 \%$ and $14 \%$, respectively. Measurements were performed in duplicates for both assays and the average result was used for data analysis.

\section{Statistical analysis}

Absolute change and percentage change over time were calculated based on patient-level pairwise data. Mean and standard deviation were reported for continuous variables and percentages were reported for categorical variables. The Wilcoxon rank-sum test was used for comparison between two groups for variables such as gender and menopause status and to evaluate changes over time. Correlation between continuous variables was assessed by Pearson's correlation coefficient and unadjusted $P$ values (two-sided) were reported. SAS ${ }^{\circledR}$ version 9.2 (SAS Institute, Cary, NC) and STATA $^{\circledR}$ version 11 (College Station, TX) were used for data analyses and boxplots, respectively. 


\section{Results}

Thirty-three patients scheduled to undergo LAGB were enrolled in this study. Three patients withdrew prior to the performance of any study-related procedures (one postponed the surgery and two failed to keep the initial appointment). A total of 30 patients (10 males, 20 females) underwent clinical evaluation and polysomnography prior to their laparoscopic procedure, followed by a fasting measurement of leptin and ghrelin. Fortyfive percent of the women $(n=9)$ were postmenopausal. The mean age of the women was $45.4 \pm 12.0$ years and for men was $41.1 \pm 13.8$ years. Hypertension was more common in males than in females ( $70 \%$ versus $40 \%$ ).

After the baseline assessment, six patients failed to keep research appointments and were withdrawn from the final data analysis. There were no statistically significant differences between those patients and the remaining group for comparisons of age, body mass index, or AHI values. The 12-month postoperative visit took place $15.3 \pm 4.0$ months after the baseline assessment and $14.5 \pm 3.2$ months after bariatric surgery. A total of 24 patients were evaluated at this endpoint, and comparative data for both time points are shown in Table 1.

Of note, the mean patient body mass index at baseline was $47.2 \pm 11.0 \mathrm{~kg} / \mathrm{m}^{2}$ (range 34.5-80.5) and was reduced to
$35.6 \pm 8.2 \mathrm{~kg} / \mathrm{m}^{2}$ postoperatively $(P<0.0001)$, corresponding to a $22.7 \% \pm 7 \%$ weight loss, $44.4 \% \pm 14 \%$ excess weight lost, and $44.4 \% \pm 16 \%$ excess body mass index one year after laparoscopic band insertion. Five patients reduced their body mass index to less than $30 \mathrm{~kg} / \mathrm{m}^{2}$ at 12 months postoperatively. Despite weight reduction, there were no statistically significant changes in blood pressure measurements or need for antihypertensive medication between the preoperative period and the 12 month postoperative follow-up. Preoperatively, 20 patients $(83.3 \%)$ had evidence of OSA (AHI $\geq 5)$, with a mean AHI of $40.5 \pm 35.1$ events per hour. The prevalence of OSA was similar between genders [eight of nine males (89\%) and 12 of 15 females (80\%)]. None of the patients with OSA were actively compliant with continuous positive airway pressure or other modalities of sleep apnea treatment.

At 12 months, there was a marked and statistically significant reduction in all measurements of sleep apnea severity when compared with baseline. Overall, there was a 44\% decrease in mean AHI values (34 versus 19 events per hour, $P<0.0001)$. Resolution of OSA was observed in three patients (all females). The prevalence of severe sleep apnea (AHI $\geq 30$ events per hour) decreased from $37.5 \%$ to $20 \%$ at 12 months postoperatively in this sample. Individual data are shown in Table 2.

Table I Vital signs, sleep study parameters, and levels of leptin and ghrelin at baseline and 12 months postoperatively in all patients

\begin{tabular}{|c|c|c|c|c|c|c|c|c|}
\hline & $\mathbf{n}^{\ddagger}$ & $\begin{array}{l}\text { Baseline } \\
\text { mean } \pm \text { SD }\end{array}$ & $\mathbf{n}^{\ddagger}$ & $\begin{array}{l}12 \text { months } \\
\text { mean } \pm \text { SD }\end{array}$ & $\mathbf{n}^{\ddagger}$ & $\begin{array}{l}\text { Absolute change } \\
\text { mean } \pm \text { SD }\end{array}$ & $\begin{array}{l}\% \text { change } \\
\text { mean } \pm \text { SD }\end{array}$ & $P$ value* \\
\hline BMI $\left(\mathrm{kg} / \mathrm{m}^{2}\right)$ & 24 & $47.18 \pm 11.01$ & 24 & $35.62 \pm 8.23$ & 24 & $-11.56 \pm 5.12$ & $-24.08 \pm 6.78$ & $<0.000$ I \\
\hline $\mathrm{SBP}(\mathrm{mmHg})$ & 23 & $123.13 \pm 14.40$ & 24 & $120.5 \pm 12.83$ & 23 & $-2.91 \pm 18.9$ & $-1.19 \pm 15.54$ & 0.49 \\
\hline $\mathrm{DBP}(\mathrm{mmHg})$ & 23 & $74.43 \pm 10.49$ & 24 & $70.17 \pm 9.31$ & 23 & $-4.44 \pm 13.32$ & $-4.18 \pm 18.37$ & 0.13 \\
\hline \multicolumn{9}{|l|}{ Sleep study } \\
\hline TST (minutes) & 24 & $346.31 \pm 73.11$ & 24 & $354.13 \pm 86.91$ & 24 & $7.81 \pm 93.89$ & $4.75 \pm 27.89$ & 0.62 \\
\hline SE (\% TST) & 24 & $77.48 \pm 10.94$ & 24 & $79.28 \pm 16.06$ & 24 & $1.80 \pm 14.86$ & - & 0.21 \\
\hline Stage I (\% TST) & 24 & $30.6 \pm 18.87$ & 24 & $23.28 \pm 10.78$ & 24 & $-7.6 \pm 17.43$ & - & 0.03 \\
\hline Stage 2 (\% TST) & 24 & $50.7 \pm 14.46$ & 24 & $54.22 \pm 11.39$ & 24 & $3.54 \pm 10.86$ & - & 0.21 \\
\hline Stage 3 (\% TST) & 24 & $6.22 \pm 5.46$ & 24 & $6.63 \pm 5.74$ & 24 & $0.48 \pm 5.85$ & - & 0.67 \\
\hline NREM sleep (\% TST) & 24 & $88.38 \pm 7.48$ & 24 & $84.6 \pm 6.0$ & 24 & $-3.95 \pm 7.11$ & - & 0.02 \\
\hline REM sleep (\% TST) & 24 & $11.65 \pm 7.48$ & 24 & $\mid 5.4 \pm 6.01$ & 24 & $3.91 \pm 7.1$ & - & 0.02 \\
\hline AHI (events/hour) & 24 & $34.2 \pm 34.97$ & 24 & $|9.00 \pm 21.7|$ & 24 & $-15.20 \pm 19.12$ & $-33.65 \pm 65.05$ & $<0.0001$ \\
\hline REM AHI (events/hour) ${ }^{\dagger}$ & 21 & $53.85 \pm 37.85$ & 23 & $38.38 \pm 28.70$ & 21 & $-19.48 \pm 27.72$ & $-28.72 \pm 19.04$ & 0.001 \\
\hline Supine AHI (events/hour) ${ }^{\dagger}$ & 23 & $41.23 \pm 35.55$ & 23 & $27.30 \pm 31.24$ & 22 & $-14.18 \pm 20.25$ & $-32.39 \pm 41.76$ & 0.0003 \\
\hline Mean $\mathrm{SaO}_{2}$ sleep (\%) & 24 & $95.15 \pm 1.84$ & 24 & $95.39 \pm 1.65$ & 24 & $0.24 \pm 1.28$ & - & 0.48 \\
\hline $\mathrm{SaO}_{2}$ nadir $(\%)$ & 24 & $80.58 \pm 6.90$ & 24 & $84.00 \pm 7.35$ & 24 & $3.42 \pm 7.91$ & - & 0.03 \\
\hline$\%$ TST at $\mathrm{SaO}_{2}<90$ & 24 & $9.22 \pm 17.84$ & 24 & $4.45 \pm 6.85$ & 24 & $-4.77 \pm 15.99$ & - & 0.005 \\
\hline \multicolumn{9}{|l|}{ Laboratory assays } \\
\hline Leptin (pg/mL) & 19 & $22.5 \pm 17.4$ & 19 & $11.9 \pm 10.7$ & 19 & $-10.6 \pm 16.6$ & $-31.7 \pm 75$ & 0.02 \\
\hline Ghrelin (pg/mL) & 16 & $1 \mid 32.6 \pm 476.8$ & 16 & $1 \mid 23.6 \pm 457.7$ & 16 & $-4 \mid \pm 384$ & $5.6 \pm 49$ & 0.99 \\
\hline
\end{tabular}

Notes: *P value was to evaluate the difference from baseline based on Wilcoxon signed rank test; ${ }^{\dagger}$ insufficient time in this stage/position ( $<3$ minutes) to determine AHI; \#lower $\mathrm{n}$ due to missing values.

Abbreviations: SD, standard deviation; BMI, body mass index; SBP, systolic blood pressure; DBP, diastolic blood pressure; TST, total sleep time; SE, sleep efficiency; REM, rapid eye movement; NREM, non-REM; $\mathrm{AHI}$, apnea-hypopnea index; $\mathrm{SaO}_{2}$, oxyhemoglobin saturation. 
Table 2 Individual data points for all patients' body mass index and apnea-hypopnea index at baseline and I 2 months postoperatively, as well as percentage of excess weight loss and change in apnea-hypopnea index at 12 months

\begin{tabular}{|c|c|c|c|c|c|c|}
\hline $\begin{array}{l}\text { Case } \\
\text { number }\end{array}$ & $\begin{array}{l}\text { Baseline } \\
\left(\mathbf{k g} / \mathbf{m}^{2}\right)\end{array}$ & $\begin{array}{l}\text { BMI I } 2 \text { months } \\
\left(\mathrm{kg} / \mathrm{m}^{2}\right)\end{array}$ & $\begin{array}{l}\text { EWL at } \\
12 \text { months (\%) }\end{array}$ & $\begin{array}{l}\text { Baseline } \\
\text { AHI }\end{array}$ & $\begin{array}{l}\text { AHI I } 2 \text { months } \\
\text { (events/hour) }\end{array}$ & $\begin{array}{l}\text { Change in } \\
\text { AHI (\%) }\end{array}$ \\
\hline 23 & 80.5 & 67.3 & $15.4 \%$ & 78.3 & 37.6 & $52.0 \%$ \\
\hline 3 & 69.7 & 43.0 & $52.2 \%$ & 3.4 & 2.0 & $41.2 \%$ \\
\hline 11 & 66.5 & 42.2 & $47.5 \%$ & 16.2 & 17.4 & $-7.4 \%$ \\
\hline 9 & 54.5 & 40.3 & $43.9 \%$ & 27.9 & 9.3 & $66.7 \%$ \\
\hline 5 & 53.6 & 40.9 & $33.7 \%$ & 12.4 & 1.4 & $88.7 \%$ \\
\hline 18 & 51.4 & 36.2 & $49.7 \%$ & 39.6 & 20.3 & $48.7 \%$ \\
\hline 22 & 47.7 & 36.1 & $46.1 \%$ & II 2.7 & 52.2 & $53.7 \%$ \\
\hline 7 & 45.6 & 37.0 & $37.9 \%$ & 5.1 & 4.0 & $21.6 \%$ \\
\hline 24 & 45.5 & 33.9 & $49.9 \%$ & 94.9 & 68.4 & $27.9 \%$ \\
\hline 21 & 45.4 & 33.9 & $53.9 \%$ & 100.6 & 79.4 & $21.1 \%$ \\
\hline 19 & 45.3 & 39.2 & $20.7 \%$ & 43.1 & 22.6 & $47.6 \%$ \\
\hline 20 & 45.1 & 35.0 & $44.5 \%$ & 66.9 & 40.9 & $38.9 \%$ \\
\hline 14 & 43.9 & 38.4 & $22.6 \%$ & 10.6 & 17.3 & $-63.2 \%$ \\
\hline 17 & 42.4 & 33.4 & $37.9 \%$ & 73.9 & 7.2 & $90.3 \%$ \\
\hline 6 & 41.8 & 26.6 & $68.3 \%$ & 13.3 & 1.8 & $86.5 \%$ \\
\hline 16 & 41.8 & 33.9 & $37.3 \%$ & 49.0 & 23.7 & $51.6 \%$ \\
\hline 2 & 40.7 & 29.0 & $63.4 \%$ & 2.4 & 0.3 & $87.5 \%$ \\
\hline 12 & 40.7 & 30.4 & $51.3 \%$ & 6.6 & 6.0 & $9.1 \%$ \\
\hline 13 & 40.5 & 29.9 & $54.2 \%$ & 15.1 & 5.9 & $60.9 \%$ \\
\hline 8 & 40.0 & 30.7 & $52.2 \%$ & 17.6 & 8.7 & $50.6 \%$ \\
\hline 4 & 39.9 & 30.2 & $50.7 \%$ & 3.7 & 12.0 & $-224.3 \%$ \\
\hline 1 & 38.1 & 30.9 & $47.7 \%$ & 1.7 & 0.2 & $88.2 \%$ \\
\hline 10 & 37.2 & 27.3 & $59.9 \%$ & 10.1 & 5.6 & $44.6 \%$ \\
\hline 15 & 34.5 & 29.2 & $25.5 \%$ & 15.8 & 11.8 & $25.3 \%$ \\
\hline Average & 47.2 & 35.6 & $44.4 \%$ & 34.2 & 19.0 & $33.6 \%$ \\
\hline
\end{tabular}

Note: Bold denotes normal AHI ( $<5$ events/hour).

Abbreviations: AHI, apnea-hypopnea index; EWL, excess weight loss; BMI, body mass index.

Fasting plasma leptin levels were significantly lower 12 months after bariatric surgery as compared with baseline values, consisting of a $31.7 \%$ decrease in mean value during this one-year period. There was no statistically significant change in fasting ghrelin levels during the study period.

\section{Secondary analyses}

When analyzed by gender, the overall AHI values were higher in men at both time measurements, as demonstrated in Figure 1. Significant improvement in AHI was seen at the 12-month postoperative assessment for both genders, but improvement was not statistically significant between the genders. No statistically significant differences were seen for changes in body mass index, leptin, or ghrelin between the genders at 12 months, as demonstrated in Table 3.

Subdividing the female patients based on menopausal status revealed increased severity of OSA at baseline in the postmenopausal group compared with premenopausal women (34.1 versus 8.7 events per hour, $P=0.001$ ). The baseline rapid eye movement $\mathrm{AHI}$ was also significantly higher in the postmenopausal women (84.5 versus 18.9 events per hour, $P=0.002)$, and this difference remained statistically significant after adjusting for body mass index $(P<0.0001)$. Among the menopausal women, there was significant improvement in the rapid eye movement sleep-related respiratory events after LAGB, which was not observed among women who were premenopausal.

\section{Correlation analyses}

The severity of OSA did not correlate with body mass index at baseline $(\mathrm{r}=0.18, P=0.40)$ or 12 months $(\mathrm{r}=0.22, P=0.31)$. Also, no significant correlation between absolute weight and sleep time spent at oxygen saturation levels below $90 \%$ was seen either at baseline $(\mathrm{r}=0.07, P=0.74)$ or 12 months $(\mathrm{r}=-0.11, P=0.60)$.

Change in leptin over time correlated with changes in body mass index and percentage of excess weight lost in this sample, although they did not reach statistical significance $(\mathrm{r}=0.32$, $P=0.19$ and $\mathrm{r}=-0.39, P=0.11$ ). Interestingly, ghrelin levels 

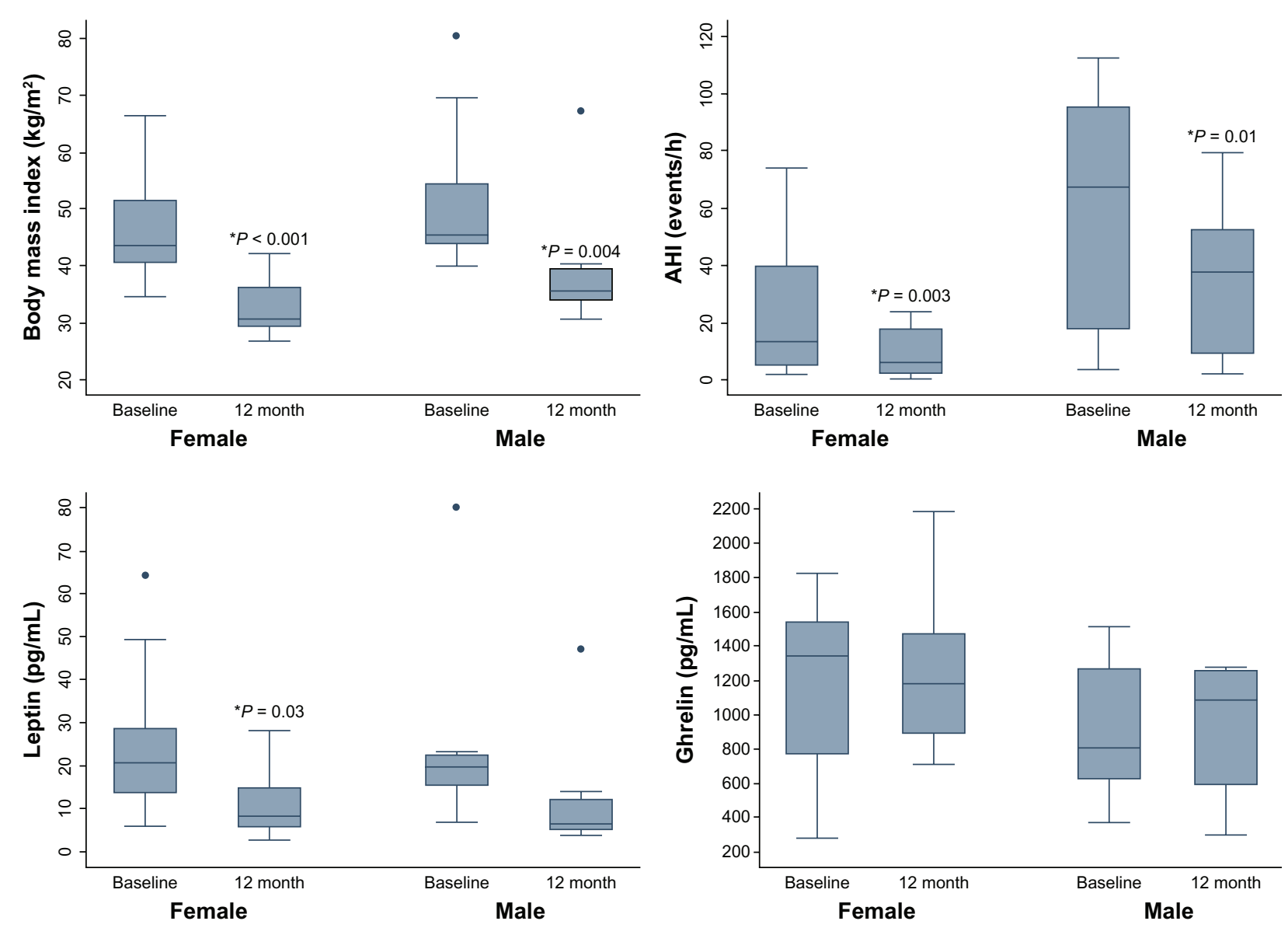

Figure I Boxplots of body mass index, apnea-hypopnea index, and leptin and ghrelin values at baseline and 12 months by gender.

Note: *Denotes statistical difference from baseline, $P<0.05$.

Table 3 Gender differences in mean respiratory and oxygen parameters during sleep at baseline and 12 months postoperatively

\begin{tabular}{|c|c|c|c|c|c|c|c|}
\hline & $\mathbf{n}$ & $\begin{array}{l}\text { Baseline } \\
\text { mean } \pm \text { SD }\end{array}$ & $\mathbf{n}$ & $\begin{array}{l}12 \text { month } \\
\text { mean } \pm S D\end{array}$ & $\mathbf{n}$ & $\begin{array}{l}\text { Absolute change } \\
\text { Mean } \pm \text { SD }\end{array}$ & $P$ values* \\
\hline \multicolumn{8}{|c|}{$\mathrm{AHI}$ (events/hour) } \\
\hline Male & 9 & $56.99 \pm 42.45$ & 9 & $35.09 \pm 27.79$ & 9 & $-21.90 \pm 20.31$ & 0.01 \\
\hline Female & 15 & $20.53 \pm 21.09$ & 15 & $9.35 \pm 8.17$ & 15 & $-11.19 \pm 17.84$ & 0.003 \\
\hline \multicolumn{8}{|c|}{ REM AHI (events/hour) ${ }^{\dagger}$} \\
\hline Male & 7 & $67.57 \pm 37.82$ & 9 & $51.27 \pm 32.66$ & 7 & $-24.64 \pm 15.69$ & 0.02 \\
\hline Female & 14 & $46.99 \pm 37.3$ & 14 & $30.09 \pm 23.42$ & 14 & $-16.90 \pm 32.35$ & 0.08 \\
\hline \multicolumn{8}{|c|}{ Supine AHI (events/hour) } \\
\hline Male & 9 & $64.04 \pm 41.76$ & 9 & $47.84 \pm 41.33$ & 9 & $-16.20 \pm 21.14$ & 0.10 \\
\hline Female & 14 & $26.56 \pm 21.77$ & 14 & $14.09 \pm 10.97$ & 14 & $-12.78 \pm 20.36$ & 0.002 \\
\hline \multicolumn{8}{|c|}{ Mean $\mathrm{SaO}_{2}$ sleep (\%) } \\
\hline Male & 9 & $94.4 \pm 1.84$ & 9 & $95.31 \pm 1.15$ & 9 & $0.91 \pm 1.64$ & 0.12 \\
\hline Female & 15 & $95.6 \pm 1.75$ & 15 & $95.44 \pm 1.93$ & 15 & $-0.16 \pm 0.84$ & 0.60 \\
\hline \multicolumn{8}{|c|}{$\mathrm{SaO}_{2}$ nadir (\%) } \\
\hline Male & 9 & $77.67 \pm 6.56$ & 9 & $82.11 \pm 6.97$ & 9 & $4.44 \pm 8.31$ & 0.15 \\
\hline Female & 15 & $82.33 \pm 6.7$ & 15 & $85.13 \pm 7.57$ & 15 & $2.80 \pm 7.88$ & 0.12 \\
\hline \multicolumn{8}{|c|}{$\%$ TST at $\mathrm{SaO}_{2}<90$} \\
\hline Male & 9 & $17.93 \pm 26.55$ & 9 & $7.24 \pm 9.00$ & 9 & $-10.69 \pm 24.70$ & 0.15 \\
\hline Female & 15 & $3.99 \pm 6.5$ & 15 & $2.77 \pm 4.76$ & 15 & $-1.23 \pm 5.93$ & 0.03 \\
\hline
\end{tabular}

Abbreviations: SD, standard deviation; BMI, body mass index; SBP, systolic blood pressure; DBP, diastolic blood pressure; TST, total sleep time; SE, sleep efficiency; REM, rapid eye movement; NREM, non-REM; $\mathrm{AHI}$, apnea-hypopnea index; $\mathrm{SaO}_{2}$, oxyhemoglobin saturation. 

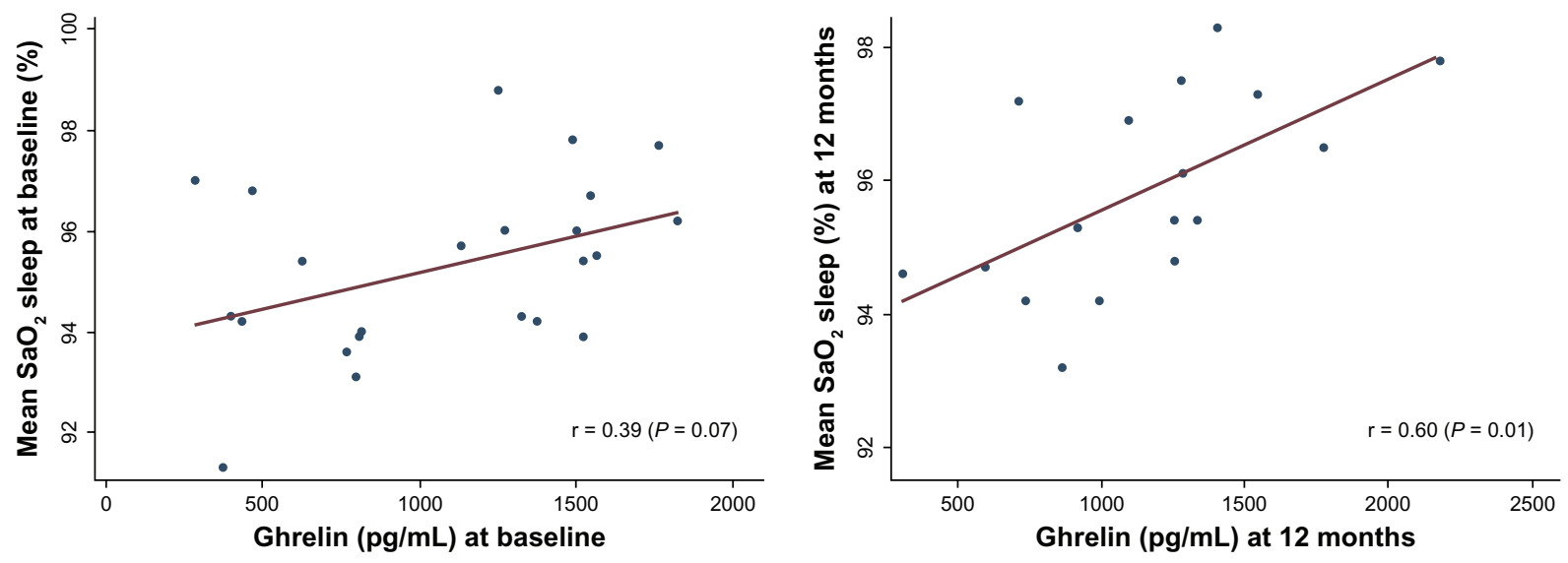

Figure 2 Relationship between ghrelin levels and mean oxygen saturation during sleep at baseline (left) and 12 months postoperatively (right).

were strongly and positively correlated with measurements of oxygen saturation during sleep at baseline $(\mathrm{r}=0.39, P=0.07)$ and at 12 months $(\mathrm{r}=0.60, P=0.01)$, as demonstrated in Figure 2.

\section{Discussion}

Laparoscopic band insertion was associated with a $22.7 \%$ reduction in weight, reflecting $44.4 \%$ of excess weight lost, and a $33.7 \%$ improvement in respiratory disturbance during sleep after 12 months in this sample. These findings reinforce the importance of weight control on the management of sleep disorders, and demonstrate that reduction in weight leads to improvement in OSA. Given the fact that OSA is strongly associated with increased cardiovascular morbidity and mortality, evaluation for this condition in all bariatric cases is of major importance and resolution of sleep apnea in the context of surgical weight reduction is possible. ${ }^{11-13}$

A relationship between obesity and sleep apnea is well described in the literature. ${ }^{14}$ Current hypotheses on the mechanisms driving this association range from an isolated mechanical effect in the airway, to physiological, metabolic, and/or inflammatory changes that alter airway physiology, impacting respiratory control and airway patency during sleep. ${ }^{13}$

Analyses of fasting levels of hormones involved in appetite and metabolic control in this sample revealed that leptin values had decreased to approximately $31.7 \%$ of baseline levels one year after laparoscopic surgery, and were positively correlated with changes in body mass index during this period. ${ }^{15}$ This finding corroborates with previously published literature. ${ }^{14,16-18}$ Reports of changes in ghrelin levels after bariatric surgery have not been consistent in the literature, with controversial findings often described. ${ }^{19-21}$ In this study, ghrelin levels were not significantly changed over the 12-month period and did not reveal an association with body mass or AHI. However, positive linear correlations between ghrelin and mean oxygen saturation levels during wakefulness and sleep were seen both at baseline and at 12 months postoperatively. This observation may suggest a potential role of ghrelin in ventilatory control, which has yet to be explored. In one animal study, accentuation of the ventilatory response to chronic hypoxemia upon exposure to exogenous ghrelin was seen, and intravenous administration of ghrelin led to improved respiratory muscle strength in a group of patients with chronic obstructive pulmonary disease. ${ }^{22,23}$ These are interesting findings that deserve further investigation. Mealtime variation in ghrelin levels could not account for the observed changes described here, because samples were obtained during morning fasting..$^{24,25}$

Several limitations of this study must be acknowledged, including its small sample size, the fact that it was not a population-based study, the potential for selection bias, and not all subjects completing their research participation. Nonetheless, these data demonstrate an improvement in respiratory disturbance and a marked reduction in leptin levels one year after a laparoscopic band procedure in a well monitored setting which included monthly surgical follow-up visits for check-up and band adjustment. The association between ghrelin and oxygen saturation levels, and the markedly greater severity of sleep apnea, including rapid eye movement-related events, in postmenopausal women are interesting exploratory findings that deserve further clinical investigation.

\section{Conclusion}

Laparoscopic bariatric surgery was an effective method of achieving substantial weight loss in patients with morbid obesity, achieving $44.4 \%$ of excess weight loss, 
accompanied by a $33.7 \%$ improvement in $\mathrm{AHI}$ and reduction in leptin levels by $31.7 \%$ at 12 months postoperatively. OSA was more severe in men and in postmenopausal women, and an association between ghrelin and mean oxygen saturation was seen in this study. Further research evaluating mechanistic approaches to OSA in obesity and the role of hormones such as ghrelin in respiratory and sleep physiology are warranted.

\section{Acknowledgment}

This work was supported by a National Institutes of Health National Center for Research Resources grant (M01 RR00096) to the New York University General Clinical Research Center.

\section{Disclosure}

CRF is an advisory board member and is on the speaker's bureau for Allergan. She has received educational and research grants from Allergan in the past. The other authors have no conflicts of interest to report in this work.

\section{References}

1. Kyzer S, Charuzi I. Obstructive sleep apnea in the obese. World J Surg. 1998;22(9):998-1001.

2. Shinohara E, Kihara S, Yamashita S, et al. Visceral fat accumulation as an important risk factor for obstructive sleep apnoea syndrome in obese subjects. J Intern Med. 1997;241(1):11-18.

3. Grunstein R, Wilcox I, Yang TS, Gould Y, Hedner J. Snoring and sleep apnoea in men: association with central obesity and hypertension. Int $J$ Obes Relat Metab Disord. 1993;17(9):533-540.

4. Klein S, Burke LE, Bray GA, et al; American Heart Association Council on Nutrition, Physical Activity, and Metabolism. Clinical implications of obesity with specific focus on cardiovascular disease: a statement for professionals from the American Heart Association Council on Nutrition, Physical Activity, and Metabolism: endorsed by the American College of Cardiology Foundation. Circulation. 2004;110(18):2952-2967.

5. Leibel RL. The role of leptin in the control of body weight. Nutr Rev. 2002;60(10 Pt 2):S15-S19.

6. Cummings DE, Shannon MH. Ghrelin and gastric bypass: is there a hormonal contribution to surgical weight loss? J Clin Endocrinol Metab. 2003;88(7):2999-3002.

7. Vgontzas AN, Bixler EO, Chrousos GP. Metabolic disturbances in obesity versus sleep apnoea: the importance of visceral obesity and insulin resistance. J Intern Med. 2003;254(1):32-44.
8. Grunstein RR, Stenlof K, Hedner J, Sjostrom L. Impact of obstructive sleep apnea and sleepiness on metabolic and cardiovascular risk factors in the Swedish Obese Subjects (SOS) Study. Int J Obes Relat Metab Disord. 1995;19(6):410-418.

9. Chapman AE, Kiroff G, Game P, et al. Laparoscopic adjustable gastric banding in the treatment of obesity: a systematic literature review. Surgery. 2004;135(3):326-351.

10. Ren CJ, Fielding GA. Laparoscopic adjustable gastric banding (Lap-Band). Curr Surg. 2003;60(1):30-33.

11. Ogretmenoglu O, Suslu AE, Yucel OT, Onerci TM, Sahin A. Body fat composition: a predictive factor for obstructive sleep apnea. Laryngoscope. 2005;115(8):1493-1498.

12. Holman ML. Obstructive sleep apnea syndrome: implications for primary care. Nurse Pract. 2005;30(9):38-43.

13. Foster GD, Borradaile KE, Sanders MH, et al; SleepAHEAD Research Group of Look AHEAD Research Group. A randomized study on the effect of weight loss on obstructive sleep apnea among obese patients with type 2 diabetes: the Sleep AHEAD study. Arch Intern Med. 2009;169(17):1619-1626.

14. Pannain S, Mokhlesi B. Bariatric surgery and its impact on sleep architecture, sleep-disordered breathing, and metabolism. Best Pract Res Clin Endocrinol Metab. 2010;24(5):745-761.

15. Pallayova M, Steele KE, Magnuson TH, et al. Sleep apnea determines soluble TNF-alpha receptor 2 response to massive weight loss. Obes Surg. 2011;21(9):1413-1423.

16. Romero-Corral A, Caples SM, Lopez-Jimenez F, Somers VK. Interactions between obesity and obstructive sleep apnea. Chest. 2010;137(3): 711-719.

17. Kendrick ML, Dakin GF. Surgical approaches to obesity. Mayo Clin Proc. 2006;81(Suppl 10):S18-S24.

18. Zhang F, Chen Y, Heiman M, Dimarchi R. Leptin: structure, function and biology. Vitam Horm. 2005;71:345-372.

19. Schindler K, Prager G, Ballaban T, et al. Impact of laparoscopic adjustable gastric banding on plasma ghrelin, eating behaviour and body weight. Eur J Clin Invest. 2004;34(8):549-554.

20. Pournaras DJ, le Roux CW. Ghrelin and metabolic surgery. Int J Pept. 2010;2010:217-267.

21. Hady HR, Dadan J, Golaszewski P. 100 obese patients after laparoscopic adjustable gastric banding - the influence on BMI, gherlin and insulin concentration, parameters of lipid balance and co-morbidities. Adv Med Sci. 2012;57(1):58-64.

22. Schwenke DO, Pearson JT, Kangawa K, Cragg PA, Shirai M. Exogenous ghrelin accentuates the acute hypoxic ventilatory response after two weeks of chronic hypoxia in conscious rats. Acta Physiol (Oxf). 2010;200(3):279-287.

23. Nagaya N, Itoh T, Murakami S, et al. Treatment of cachexia with ghrelin in patients with COPD. Chest. 2005;128(3):1187-1193.

24. Cummings D, Purnell JQ, Frayo R, Schmidova K, Wisse BE, Weigle DS. A preprandial rise in plasma ghrelin levels suggest a role in meal initiation in humans. Diabetes. 2001;50(8):1714-1719.

25. Ulukavak Ciftci T, Kokturk O, Bukan N, Bilgihan A. Leptin and ghrelin levels in patients with obstructive sleep apnea syndrome. Respiration. 2005;72(4):395-401.
International Journal of General Medicine

\section{Publish your work in this journal}

The International Journal of General Medicine is an international, peer-reviewed open-access journal that focuses on general and internal medicine, pathogenesis, epidemiology, diagnosis, monitoring and treatment protocols. The journal is characterized by the rapid reporting of reviews, original research and clinical studies across all disease areas.

\section{Dovepress}

A key focus is the elucidation of disease processes and management protocols resulting in improved outcomes for the patient. The manuscript management system is completely online and includes a very quick and fair peer-review system. Visit http://www.dovepress.com/ testimonials.php to read real quotes from published authors. 